\title{
Thought Space Wānanga-A Kaupapa Māori Decolonizing Approach to Research Translation
}

\author{
Linda Smith ${ }^{1, *}$, , Leonie Pihama ${ }^{2}$, Ngaropi Cameron ${ }^{3}$, Tania Mataki ${ }^{4}$, Hinewirangi Morgan ${ }^{5}$ \\ and Rihi Te Nana ${ }^{2}$ \\ 1 Faculty of Māori and Indigenous Studies, University of Waikato, Hamilton 3240, New Zealand \\ 2 Ngā Wai a Te Tūī Māori and Indigenous Research Centre, Unitec, Auckland 1025, New Zealand; \\ lpihama@unitec.ac.nz (L.P.); rtenana@unitec.ac.nz (R.T.N.) \\ 3 Tu Tama Wahine o Taranaki, New Plymouth 4310, New Zealand; Ngaropi.Cameron@tutamawahine.org.nz \\ 4 Te Puna Oranga Inc., Christchurch 8062, New Zealand; ariana@tepunaoranga.co.nz \\ 5 Independent Consultant, Hamilton 3204, New Zealand; hinewirangi@xtra.co.nz \\ * Correspondence: tuhiwai@waikato.ac.nz
}

Received: 29 October 2019; Accepted: 9 December 2019; Published: 16 December 2019

check for updates

\begin{abstract}
This paper discusses an indigenous Māori approach, named Thought Space Wānanga, for sharing knowledge and accelerating the translation of research into practical outcomes through transformational practices, policies, and theory development. In contexts such as New Zealand, there is an increasing demand on all publicly funded researchers to demonstrate the impact of their research and to show pathways for achieving social and economic outcomes from single, focused projects. Knowledge translation is the most common term used to describe the link between research and impact and the process of turning research into results. While it is highly debatable whether planning for this at the front end of research will necessarily lead to such high-level outcomes being achieved, many indigenous researchers aim for their research to be translated into real world positive outcomes for indigenous communities. Thought Space Wānanga is a facilitated process framed within Māori cultural protocols, designed to help indigenous Māori researchers meet that aspiration.
\end{abstract}

Keywords: indigenous methodologies; knowledge translation; kaupapa māori

\section{Introduction}

\section{Kaupapa Māori: A Decolonising Approach to Research Translation}

The paper provides a discussion of key ideas around indigenous notions of knowledge sharing, co-production of Indigenous knowledge, knowledge translation and the specific challenges for indigenous researchers whose work is framed by indigenous knowledge and methodologies. It explains the design and structure of Thought Space Wānanga, with an example of how it was used in this research project, and provides a critical discussion of a designed method that keeps to the principles of indigenous methodologies while meeting the challenges related to achieving greater translation of research into useful outcomes. The first part of the paper brings together a discussion about Indigenous methodologies, knowledge translation and kaupapa Māori. The second half of the paper discusses the principles of a Thought Space Wānanga. The paper concludes with a brief discussion of the policy context for Māori research.

One of the key dimensions of indigenous methodologies is an explicit intention to connect with and serve the interests of indigenous communities and share research knowledge with those who helped create it, as an acknowledgement of their tino rangatiratanga or self-determining status and as an expression of the principle of reciprocity (Smith 1999). Furthermore, knowledge sharing helps 
communities to share their knowledge directly in modes and media that they control with other communities, without the researcher as the expert mediator of knowledge or the funding agency, which in most cases in New Zealand is the Government, accumulating knowledge that perpetuates a view that the settler state knows what is best for Indigenous Peoples (Moewaka Barnes et al. 2011). The idea of sharing knowledge is informed by some powerful indigenous concepts about collective well-being, collective responsibility and collective accountability (Morton Ninomiya et al. 2017). Knowledge sharing positions the knowledge gained through the direct participation of Indigenous participants as a potential collective benefit.

Indigenous motivations for knowledge sharing also come from colonial experiences that have excluded Indigenous Peoples from access to knowledge, have used knowledge to erase Indigenous experiences, and have denied that Indigenous Peoples are creators of knowledge (Moewaka Barnes et al. 2011; Smylie 2011). Knowledge sharing has become a way to cut across relations of power, not by 'talking up to power' but by talking across power to each other, enhancing connections and relationships. Sharing knowledge is a strategy for decolonizing the ways in which knowledge institutions create rules and norms around such things as research translation or research impact. Shared knowledge is expressed through a range of approaches that have enhanced community engagement strategies and encouraged the publication and performance of materials that report back to the community as a key audience and end-user of research (Cooper and Dreidger 2018). It is a given in many indigenous methods, especially in health and education, that knowledge sharing strategies are co-designed with communities at the start of a project, are considered part of relationship building and are hardwired into the research methodology (Lavallee 2009). The use of film, multi-media, digital and social media platforms and performance alongside the more typical forms of publication have made this aspect a very exciting space for indigenous knowledge sharing.

\section{The Epistemic Possibilities for the Translation of Indigenous Research}

There are many excellent examples of indigenous research influencing indigenous organizational development, capacity building, service delivery and cultural revitalization strategies (Mertens et al. 2013). There are far fewer examples of indigenous research, meaning research applying indigenous methodologies, undertaken by indigenous researchers with indigenous communities, influencing public policy agencies or changing the practices of the professional groups most likely to interact with indigenous communities, such as health and education professionals, psychologists, judges and lawyers, law enforcement and corrections officials. An exception to this is the work of Mason Durie (1994, 1998, 2001, 2006) in New Zealand, whose research has targeted Māori health and well-being. The more common experience involves settler state governments applying knowledge from somewhere else and imposing it on Indigenous communities (Moewaka Barnes et al. 2011) or appropriating cultural concepts in programme designs and interventions and then slowly erasing their indigenous elements and origins; for example, the Family Group Conference Model in New Zealand or Sentencing Circles in Canada. To illustrate this latter, point Family Group Conferences were developed in New Zealand in 1989, based on Māori cultural concepts of mediation, and have been applied across the world as an innovative community and family centered restorative practice. However, no reference is made to the indigenous philosophies, rational and practices that made them so innovative (McElrea 1998; Hillebregt et al. 2018).

In the wider research literature, the term 'knowledge translation' is more familiar than knowledge sharing. It is a term more frequently used in the health, science and technology, business and public policy areas. Introduction of the term is attributed to the Canadian Institutes of Health Research (CIHR), which originally defined it as "the exchange, synthesis and ethically-sound application of knowledge-within a complex system of interactions among researchers and users-to accelerate the capture of the benefits of research for Canadians through improved health, more effective services and products, and a strengthened health care system" (Canadian Institutes of Health Research (CIHR) 2004 , p. 2). This definition captures the emphasis that neoliberal public policy approaches take in 
relation to demonstrating value for money from public investment in research through improved health outcomes, improved services, innovative and effective health products and a strong health care system. Other approaches have expanded this definition and applied it to domains and sectors beyond public health research.

Knowledge translation definitions, of which there are many, tend to emphasize processes and pathways through which knowledge produced by research is translated from one form to another form, so it is made ready for policy, practice outcomes, technology transfer and commercialization opportunities (Strauss et al. 2009). This has also been defined as the 'know-action' gap (CIHR 2004). However, these processes are problematic because the knowledge users are themselves fraught with complexities and dynamics that offer no guarantee or assured outcomes and no 'soft-landing' for knowledge. Next-user and end-user expectations can often be simplistic and instrumental; it is as if the process resembles a production line from input to output, which is linear, unidirectional, time bound and delivered in a 'ready to use package' (Alvarez et al. 2010). Those who write about knowledge translation as a 'thing in itself', or as a particular problem area for creating a knowledge economy, see it as a dynamic, challenging, often circular and multidirectional process at its best (Rich 2001).

Translating knowledge goes well beyond the more traditional notion of research dissemination. It counters the liberal academic idea that research should simply be published in a peer-reviewed journal and 'taken up' by others in whatever form they may choose without any direct researcher engagement or responsibility. In the New Zealand context, there have been explicit requirements for researchers to address such items as 'implementation pathways', 'proposed economic impacts', 'knowledge implementation plans' and 'technology transfer' in project proposals. These requirements have forced researchers to either take greater responsibility for the post-research process or to share responsibility for the research as a whole. Some of the practical strategies that have been used by researchers are to negotiate formal agreements with stakeholders around intellectual property; undertake direct engagement with Government agencies to align their research with policy cycles; and to produce user-friendly resources.

In decolonizing and Indigenous research methodologies, knowledge and ways of knowing as epistemological and ontological concepts are held together in a productive tension. Indeed, some indigenous languages may not differentiate the epistemological from the ontological as the words for knowledge and knowing may be the same. An example of this will be discussed later, around the concept of Wānanga. Knowledge sharing and knowledge reciprocity value the collective responsibility for knowledge as it journeys and shifts shape and form, from empirical to spiritual, from story to policy, from evidence to performance, from report to dialogue, from protest to policy. Knowledge sharing honours the connection between the people who helped produce the knowledge and the diverse forms into which knowledge can be transformed (Cram and Mertens 2015). Knowledge is considered part of the relational world and an important dimension of transforming colonial conditions and informing decolonizing futures (Moewaka Barnes et al. 2011; Smith et al. 2016; Tuck et al. 2018).

\section{Kaupapa Māori Co-Production of Knowledge}

Indigenous research approaches grapple with two interwoven threads of inquiry. The first is based on self-determination and indigenous sovereignty, and the second on decolonizing knowledge and systems (Smith 1999). The self-determination and sovereignty line of enquiry focuses on such things as Indigenous knowledge, methodologies, language and cultural revitalization, indigenous nationhood, governance and well-being, Indigenous philosophies, visions, aspirations and the exercise of Indigenous rights. The second approach focuses on reframing knowledge systems, engagement and participation with systems of the settler nation state, recognition of Indigenous rights, reconciliation strategies, social justice and wider social and economic transformation.

The role of knowledge is critical in both threads of inquiry. The international literature uses terms such as traditional knowledge, traditional ecological knowledge (TEK), Indigenous knowledge, local knowledge and tribal knowledge (Smith et al. 2016; UNESCO 2019). Traditional knowledge 
includes diverse types of knowledge, not just the knowledge of Indigenous Peoples, and is generally viewed as understandings and practices that are passed down mostly unchanged over generations. It is the knowledge that pre-dates research and modernity. Traditional ecological knowledge is the specific field of ecological environmental knowledge that has been documented by ecologists, biologists and environmental scientists. Indigenous knowledge is explicitly linked to the emergence of an international Indigenous rights movement, the UN Declaration of the Rights of Indigenous Peoples and recognition as self-determining Peoples (Mead and Ratuva 2007; Posey 2004).

A critical understanding in relation to Indigenous knowledge is that Indigenous Peoples have continued to create and produce knowledge despite the impacts of colonization (Smylie 2011; Smith et al. 2016). While their cultural and social adaptation strategies for survival have been dismissed as evidence of the demise of their knowledge and loss of identity, they have in fact integrated new knowledge, new places, new relations, new circumstances and new references into what and how they know. Those Indigenous Peoples who still survive to claim their identity did not suddenly stop knowing, imagining or creating stories, narratives, meanings and insights. This idea is summed up nicely in the question asked by Lear in his book Radical Hope Ethics if the Face of Cultural Devastation (Lear 2008)-What do we do ethically when faced with complete cultural devastation? As answered more than a hundred years ago in a Māori haka, Ka mate, ka mate, ka ora, ka ora. We die, we die or we live, we live. By living we continue to breathe, to dream, to create, to know and to be. Indigenous Peoples have had to rely upon the conceptual resources, instructions, wisdom and tenacity of their ancestors to survive colonization. It has taken more than resilience and resistance and its cost has been devastating for Indigenous languages, cultures and nations.

Understanding these points opens possibilities for contemplating Indigenous knowledge as constantly evolving, with the potential to create and co-create new Indigenous knowledge that fits with our times and contexts while remaining connected to our values and identities. Co-design, co-production, participatory action and Indigenous research approaches provide methods and strategies that facilitate, and at their best ignite the emergence of new research knowledge and new Indigenous knowledge (Parsons et al. 2016). In the wider context, co-design and co-production are strategies used across different development projects, professional and institutional domains, science and policy, and real-life change programmes involving multi-disciplines, multi-stakeholders multi-funders and multi-next users. (Jasanoff 2004) In most cases where Indigenous communities are involved in co-production, the aim is to facilitate opportunities for Indigenous knowledge to inform the production. Indigenous communities are not normally the hosts of co-production projects and Indigenous knowledge is not normally the 'norm' knowledge in the room. A Kaupapa Māori approach to co-production assumes that Māori are the principal hosts and Māori cultural protocols will inform the taken-for-granted social processes of any gathering of stakeholders and experts; that Māori knowledge is a critical part of the discussion and designing of solutions; and that Māori participation includes but is not limited to formal and ceremonial processes.

The knowledge translation challenge for decolonial and Indigenous methodologies is to ensure that research knowledge has a positive transformative impact for Indigenous communities and contributes to Indigenous aspirations for self-determination and well-being (Moewaka Barnes et al. 2011; Smith 2012). If public policy agencies struggle to cater for, engage with and provide active support for Indigenous concerns, how then does Decolonizing and Indigenous Research get heard, engaged with and included in policy making? Put more simply, how does decolonial and Indigenous research talk up to Power? And how can Power engage with Indigenous knowledge in productive ways to create social benefits? Similar questions can be framed around influencing practice, system behaviour, intervention and programme designs, product development, service delivery, evaluation approaches, community knowledge and public understandings. 


\section{Thought Space Wānanga: Principles and Protocols}

Thought Space Wānanga is based on principles of Kaupapa Māori theory and research, and other indigenous methodologies, including Indigenous principles and protocols around respect, relevance, reciprocity, and responsibility (Kirkness and Barnhardt 2001; Pihama 2012). Kaupapa Māori research principles, as first articulated by Smith, (Smith 2005) identify the importance of indigenous identity, stories and knowledge, relationships and collective responsibilities, the need for research to address and mediate the challenges we face, the normality of being Māori or being indigenous, and the significance of Māori cultural protocols and language.

The relational dimensions of Indigenous knowledge, ways of knowing and being, and relationships between humans and their environments are critical to the design values of Thought Space Wānanga. The Māori word wānanga is used as both a noun and a verb. As a noun, it is defined as tribal knowledge including philosophy, as an instructor and wise person and as a seminar, conference or forum. A Whare Wānanga is a traditional institution of learning and describes the formal teaching and learning philosophies, pedagogies and protocols that were practiced when the wānanga was in session. As a verb it means to meet, to discuss, to deliberate. A shorthand way, in the English language, of understanding this dual use is that a wānanga is a space/place that people attend to wānanga about a topic of focus. Pohatu and Warmenhoven (2007, p. 120) say that "through wānanga we are able to reflect and (be) reminded of our place in the universe". They highlight that Wānanga provide a culturally determined space for the wise transmission of knowledge and that Wānanga disrupt and decolonize traditional western methods by positioning the collective production of knowledge as central, including knowledge translation, rather than just relying on research outputs and a repositioning of researcher/researched relationships.

We have drawn on the protocols, structure, processes and wise practices of community-based wānanga that have been used for generations, to conceptualize a contemporary space/process to share research knowledge. We envisaged the space as one that would stimulate policy and practice discussions and co-design effective translational strategies for communities. Wise practices offer a more inclusive approach to Indigenous ideas about good practices (Stout 2017). These ideas have been refined through a series of research projects that have considered ways to reinvigorate the exercise of Indigenous intellectual and cognitive sovereignty and affirm a decolonizing of the mind (Smith 2018). The protocols of Thought Space Wānanga include mihimihi or greetings; karakia or acknowledgements; whakawhanaungatanga or relationship building; a commitment to the kaupapa (purpose of the Wānanga); kai (food); and poroporoaki (closure, reflections and farewells). Each protocol is considered critical to transitioning people through time and space to make the Wānanga and each participant open and ready intellectually, emotionally, spiritually, socially and relationally. In a Māori community context, these protocols can be more or less formal and long, or more or less informal and brief; in other words, they vary according to specific Iwi contexts and circumstances. Rather than seek to fix cultural protocols in contemporary contexts as if Māori culture is one-dimensional, we have evolved our protocols using a 'more or less' approach based on our context and circumstances, our participants and our resources.

The thought space dimension signifies that the expectations of the Wānanga are for participants to engage in active and collective thinking and problem solving; not just 'talk'. While in Wānanga, or in session, tikanga (practices and protocols) dictate the expectation that what is said in the room stays in the room. The participants are invited because of their expertise as professionals, policy analysts, leaders of providers, key influencers in Government agencies and community activists. The protocols of the Wānanga create a space that is safe and in which participants are free to think openly and outside their specific organizational employment roles.

\section{Structuring the Thought Space Wānanga}

Thought Space Wānanga can be planned as a sharply focused 3-h session or expanded to a 2-day session, depending on the scope of the topic. The session is facilitated by a senior researcher who 
guides the participants through the whole process. After the opening protocols, the facilitator sets out the expectations and the plan for the day. The session typically begins with a stimulus presentation that goes through the research and offers tentative, mostly high-level findings. Sometimes an international expert in the field has been invited to set a wider context for Indigenous Peoples. This is effective in widening the frame of reference for participants beyond their experiences and immediate concerns. The thinking work of the participants is set by the facilitator, who leads the Wānanga through a series of group activities designed to synthesize knowledge, explore applications, identify limitations and highlight other possible scenarios. The intentions are to provoke deep-level thinking, test the credibility of the findings at a practice level and then apply that thinking to specific contexts, which may be policy, provider, community or practitioner oriented. The activities are designed as short, intense bursts, each lasting about an hour. The senior researcher' role is to guide participants into a mode of deep thinking by preparing the participants from the start and leading them through the process. The team have found that the challenge to reaching a state of deep thinking is not the length of time but the ability to ensure that every participant is 'present' in the wānanga.

Some of the Kaupapa Māori and decolonizing pedagogical tools that may be used during a Wānanga include sessions on the relevant mātauranga concepts; framing and reframing of language and discourse; indigenous story work; building transforming agenda; collective ownership and leadership; solutions focused for providers, clinicians, community organizations, and government agencies; and developing more powerful media strategies. Activities take place with large or small groups, which may be specially selected by the research team, or randomly brought together, or may involve the entire Wānanga, including support staff.

In one example of a Thought Space Wānanga, we invited 150 participants through the networks of providers working in the area of trauma informed care. These networks included Māori and other social service workers, portfolio managers from Government Agencies, individual professionals and social media contacts. The research project that was the focus of the Wānanga was coming to an end and the research team were able to present tentative ideas and findings to participants for feedback. Participants could also question and think about the relevance or implications of the project for their work. They were able to ask questions about the methods and limitations of the research.

Professor Linda Tuhiwai Smith facilitated the Wānanga and took participants through a series of group discussions designed to share their own work with each other, synthesize their learnings from earlier speakers, critically discuss their own theories of practice and practices of theory, and co-design some new practice and policy strategies. The participants had different professional roles; for example, health workers, home health carers, drug and alcohol counsellors, psychologists, social service provider managers, Government policy analysts, elders and community advocates. The discussion groups were self-selected initially and then augmented with smaller groups merged into larger groupings. The role of the facilitator was important in stimulating the discussions and taking everyone through a process with expected outcomes. This included being clear about respecting each other, sharing from an open-hearted place, and working together to design solutions. The cultural values were embedded with the use of Māori language. Evaluation forms were given out at the end of the Wānanga.

In Kaupapa Māori and Indigenous research, there is a very powerful driver to translate research into positive and transformative outcomes for Indigenous Peoples, nations, communities, and families (Chillisa 2011; Robson and Harris 2007; Wallerstein and Duran 2006). Being committed to sharing knowledge and translating research into direct and positive transforming outcomes is something researchers have to express, think through and anticipate in their projects (Smith 1999; Tuck 2009). The research is also expected to answer questions the Indigenous community may have rather than questions the settler state has, using methods that communities find meaningful and relevant. This is a critical intent of Indigenous research (Smith 1999). Therefore, we must provide a range of translation activities that align to the aspirations of Indigenous communities. We have seen an increase in creative processes such as art exhibitions, digital storytelling, children's storytelling and feature documentaries as knowledge translation processes and outputs. These processes are decolonizing in that the focus of 
such knowledge translation prioritizes Indigenous communities rather than settler state governments and their agencies. The Thought Space Wānanga process used in this project is one such mechanism, through which the research team sought to ensure that engagement with government agencies, social service providers and organisations and those involved in policy development was a purposeful part of the research translation process.

\section{Māori Research and Public Policy}

In Aotearoa, the main 'official' driver for improving research translation is the government and research funding mechanisms. As the largest funder of research, the government wants to see 'value for money' and a translation of publicly funded research into wealth in this country. This approach clearly links knowledge creation to wealth creation and is a view embedded in the embrace of neo-liberal economic thinking by successive governments. Knowledge creation for its own sake is supported through only source of one funding, while most funded research is expected to deliver outcomes and impacts. In this environment, research institutions have had to build infrastructures with dedicated resources to support research translation. Most of the effort and support is in the commercialization space, with an emphasis on intellectual property, technology transfer and the development of startup companies.

In the social space, there is also an expectation that research will provide evidence for social policies. The notion of evidence-based public policy is as much a driver for research translation as is commercialization. However, as many others have noted already, the pathways from research to public policy are not straightforward across domains ranging from health to science and technology (Boaz et al. 2011; Jasanoff 2009). As argued by Boaz et al. (2011) in terms of health research 'challenges remain in translating research into policies and practices that improve patient care.' Similarly, Jasanoff (2009) addresses the challenges for policy makers to draw on science knowledge to inform their work. Indeed, what constitutes 'evidence' and how evidence stacks up against political campaign promises is part of what is contested in the process of making or changing policy. There are multiple reasons why research and policy may be disconnected from each other. Research currently relevant to policy may have been completed years ago or not undertaken at all because the questions are new. New research may present findings and implications for which there is no obvious policy agenda. The government has other priorities. Research may be answering questions government has no interest in resolving. Policy officials may not see the implications of research in their work, or have a strong view of what research they need to consider and what research is not worthy of their attention. Ministers of Government, Parliamentary Select Committees, Government Reviews, Commissions and the sheer churn of policy work makes for a dynamic context in which research itself may not be a priority. This all assumes, of course, that science, truth and reliable knowledge actually matter in national and international governance, which is not a stable proposition in many countries.

In seeking to influence policy change on a national level it may seem natural that all three drivers of translation: government economic policies, government social policies, and Indigenous research, would converge seamlessly into a synergy of translation. However, as other Indigenous researchers have stated, the relationship between a settler state government and Indigenous Peoples is deeply problematic (Coulthard 2014). A relationship forged in contexts of invasion, war, colonization, assimilation, cultural destruction, Treaty betrayals, the seizing of lands, and forced removal of children, which have continued through to the 21st Century without seriously addressing Indigenous rights, is not the best formula for working together to co-produce policy for mutual benefit. Even in countries like New Zealand, which have undertaken a number of Treaty of Waitangi Settlements with Iwi (Māori tribes/collectives) and have had some history of engaging in Māori ideas and language, there remains a fundamental failure to address the core structural issues that challenge the assumption of settler state sovereignty. Research that is led by Māori and engages with Māori communities is still marginalized by Government agencies, despite their claims to be creating evidence-based policy. Even when included in policy discussions and invited as experts to participate in making policy representing 'the Māori 
voice' is inevitably part of an asymmetrical process that consigns Māori research and ideas to a limited array of speaking parts.

\section{Summary}

Thought Space Wānanga provides a space within research to engage in Kaupapa Māori methods in the knowledge translation and dissemination space. It is important to share this process as an example of decolonising and transforming knowledge translation as it has had a significant impact on the sharing of the findings of this research with a wide range of Māori groups and organisations that are engaged in providing support in the area of trauma healing. There are opportunities and constructive challenges in facilitating conversations with a diverse group of participants, even when they are mostly Māori or Indigenous. One of the significant challenges was related to the roles and boundaries of the many professional groups who work in the trauma informed care arena. These professions, including social work, nursing, psychology, counselling and medicine, are governed by their professional codes of conduct, professionally guarded paradigms of care and protocols for working together in western clinical contexts. These relationships often function within a hierarchy of status in clinical settings, although demarcated by their distinct specialisms. If not invited explicitly to think above and beyond their professional backgrounds the potential to 'talk past each other' or 'talk around each other' can be very limiting. For those outside that matrix of professions, including clients and the victims of trauma, the boundaries and discourses can be difficult to understand and frustrating to unpack. This can be even more profound for Māori and 'Other' groups who are generally seen by mostly white professionals.

Māori social service providers that are not western-based clinics generally seek holistic and collaborative approaches grounded in kaupapa Māori protocols and practices, and there is a greater insistence that professionals work collaboratively. Mātauranga Māori and tikanga (practices) were used to reframe the conceptual and discursive way 'the problem of trauma' was defined in current trauma informed care practice. Participants were invited to think in a relational, indigenous and Māori knowledge framework, and to use that thinking to generate insights into the ways in which trauma work involves relational concepts and care strategies. These include different epistemic understandings of western ideas about mind/body, individual/collective, self/other, illness/wellness, and dependence/independence. The task is not to ditch current good practices but to understand why many good practices do not work well with Māori and to adapt and incorporate, if not transform, their practice models. Thought Space Wānanga provides an opportunity to reach deeply into the collective skills present in the Wānanga to co-design new strategies that can be taken back or taken up to their work settings.

One of the significant opportunities provided by the Wānanga was to share knowledge and practice across contexts. Policy experts were able to feed in current or new policy thinking and suggest ways to influence policy discussions. Providers were able to share their experiences with funding or sustainability issues in their organisations and discuss strategies of mutual benefit. All groups had many stories to tell about their successes and frustrations. The process of infusing policy and provider thinking with the ideas and findings from the research was useful as a translation process but clearly more has to happen to shepherd research findings all the way through to impact.

What happened next? This particular Thought Space Wānanga provoked immediate responses from some participants who were senior leaders in their organizations. Some of the providers sought permission to use our kaupapa Māori framework in their practices. Other providers became proactive in providing professional development for their staff so they could engage in Kaupapa Māori trauma informed care strategies. The research team were invited by policy agencies to present their research and hold a symposium in Wellington where public policy agencies are located, so that more colleagues could attend. One discursive change that Māori research has influenced more broadly is the wider use of terms such as intergenerational historic trauma, trauma informed healing and the linking of colonial actions to trauma and healing in the 21st Century. 
Author Contributions: Conceptualization, L.S. and L.P.; methodology, L.P.; formal analysis, L.P., L.S., N.C. and R.T.N.; writing-original draft preparation, L.S.; writing, review and editing, L.S., L.P., N.C., T.M., H.M. and R.T.N.; funding acquisition, L.P.

Funding: This research was funded by the Health Research Council of New Zealand, 104547.

Conflicts of Interest: The authors declare no conflict of interest.

\section{References}

Alvarez, S., B. Douthwaite, G. Thiele, R. Mackay, D. Córdoba, and K. Tehelen. 2010. Participatory Impact Pathways Analysis: A practical method for project planning and evaluation. Development in Practice 20: 946-58. [CrossRef]

Boaz, A., J. Baeaza, and A. Fraser. 2011. Effective Implementation of research into practice: An overview of systematic reviews of the health literature. BMC Research Notes 4: 212. [CrossRef] [PubMed]

Canadian Institutes of Health Research. 2004. Knowledge Translation Strategy 2004-2009: Innovation in Action; Otawwa: Canadian Institutes of Health Research.

Chillisa, B. 2011. Indigenous Research Methodologies. Thousand Oaks: Sage.

Cooper, E.J., and S.M. Dreidger. 2018. Creative, strengths-based approaches to knowledge translation within Indigenous health research. Public Health 163: 61-66. [CrossRef] [PubMed]

Coulthard, G. 2014. Red Skin, White Masks: Rejecting the Colonial Politics of Recognition. Minneapolis: University of Minnesota Press.

Cram, F., and D. Mertens. 2015. Transformative and Indigenous Frameworks for Multimethod and Mixed Methods Research. Oxford: Oxford Handbook of Multimethod Research.

Durie, M. 1994. Whaiaora-Mäori Health Development. Auckland: Oxford University Press.

Durie, M. 1998. Te Mana Te Kawanatanga: Policies of Mäori Self-Determination. Auckland: Oxford University Press.

Durie, M. 2001. Mauri Ora: The dynamics of Mäori Health. Auckland: Oxford University Press.

Durie, M. 2006. Measuring Māori Wellbeing. Wellington: New Zealand Treasury. Available online: www.treasury. govt.nz (accessed on 11 December 2019).

Hillebregt, C., E. Scholten, M. Ketelaar, M.W.M. Post, and J.M.A. Visser-Meily. 2018. Effects of Family Group Conferencing among high-risk patients of chronic disability and their significant others: study protocol for a multicenter controlled trial. BMJ Open 8: e018883. [CrossRef] [PubMed]

Jasanoff, S., ed. 2004. States of Knowledge: The Co-Production of Science and Social Order. Paperback Edition 2007. London: Routledge.

Jasanoff, S. 2009. The Fifth Branch: Science Advisors as Policymakers. Cambridge: Harvard University Press.

Kirkness, V., and R. Barnhardt. 2001. First Nations and higher education: The four Rs-Respect, relevance, reciprocity, responsibility. Journal of American Indian Education 30: 9-16.

Lavallee, L. 2009. Practical Application of an Indigenous Research Framework and Two Qualitative Indigenous Research Methods: Sharing Circles and Anishnaabe Symbol-Based Reflection. International Journal of Qualitative Methods 8: 21-40. [CrossRef]

Lear, J. 2008. Radical Hope-Ethics in the Face of Cultural Devastation. Cambridge: Harvard University Press.

McElrea, J.F. 1998. The New Zealand Model of Family Group Conferencing. European Journal on Criminal Policy and Research 6: 527-43. [CrossRef]

Mead, A., and S. Ratuva. 2007. Pacific Genes and Life Patents: Pacific Experiences and Analysis of the Commodification and Ownership of Life. New York: The United Nations University Institute of Advanced Studies and Call of the Earth Llamada de la Tierra.

Mertens, D.M., F. Cram, and B. Chillisa. 2013. Indigenous Pathways into Social Research: Voices of a New Generation. Walnut Creek: Left Coast Press.

Moewaka Barnes, H., W. Henwood, S. Kerr, V. McManus, and T. McCreanor. 2011. Knowledge Translation and Indigenous Research. In Knowledge Translation in Context. Edited by Elizabeth M. Banister, Bonnie J. Leadbeater and E. Anne Marshall. Toronto: University of Toronto Press, pp. 161-80.

Morton Ninomiya, M.E., D. Atkinson, S. Brascoupe, M. Firestone, N. Robinson, J. Reading, C.P. Ziegler, R. Maddox, and J. Smylie. 2017. Effective knowledge translation approaches and practices in Indigenous health research: a systematic review protocol. Systematic Reviews 6: 34. [CrossRef] [PubMed] 
Parsons, M., K. Fisher, and J. Nalau. 2016. Alternative approaches to co-design: insights from indigenous/academic research collaborations. Current Opinion in Environmental Sustainability 20: 99-105. [CrossRef]

Pihama, L. 2012. Kaupapa Māori Theory: Transforming theory in Aotearoa. He Pukenga Kōrero 9: 5-15.

Pohatu, P., and T. Warmenhoven. 2007. Set the overgrowth alight and New Shoots will Spring Forth: New Directions in Community Based Research. AlterNative 3: 108-27. [CrossRef]

Posey, D. 2004. Indigenous Knowledge and Ethics: A Darrell Posey Reader. New York: Routledge.

Rich, R.F. 2001. Social science Information and Public Policy Making. New Brunswick: Transaction Publishers.

Robson, B., and R. Harris, eds. 2007. Hauora Maori Standards of Health IV: A Study of the Years 2000-2005. Wellington: te Rōpū Rangahau Hauora a Eru Pomare, University of Otago.

Smith, G.H. 2005. Beyond Political Literacy: From Conscientization to Transformative Praxis: What Difference Does Research Make and for Whom? In Counterpoints. Bern: Peter Lang AG, vol. 275, pp. $29-42$.

Smith, L.T. 1999. Decolonizing Methodologies Research and Indigenous Peoples. London: Zed Books.

Smith, L.T., T.K. Maxwell, H. Puke, and P. Temara. 2016. Indigenous knowledge, methodology and mayhem: What is the role of methodology in producing indigenous insights? A discussion from Mātauranga Māori. Journal of Knowledge Cultures 4: 131-41.

Smith, L.T. 2012. Decolonizing Methodologies Research and Indigenous Peoples, 2nd ed. London: Zed Books.

Smith, L.T. 2018. Indigenous Insights on valuing complexity, sustaining relationships, being accountable. In Solving Wicked Problems in Complex Evaluation Ecologies of Inequity and Inequality. Edited by R. Hopson and F. Cram. Palo Alto: Stanford University Press.

Smylie, J. 2011. Knowledge Translation and Indigenous Communities: A Decolonizing Perspective. In Knowledge Translation in Context. Edited by E.M. Banister, B.J. Leadbeater and E.A. Marshall. Toronto: University of Toronto Press, pp. 182-200.

Stout, M.K.D. 2017. Emergent Principles and Protocols for Indigenous Health Service Evaluation: Summary Report of a Provincial "Three Ribbon" Expert Consensus Panel. Toronto: Well Living House, Center for Urban Health Solutions, St Michael's Hospital.

Strauss, S.E., J. Tetroe, and I. Graham. 2009. Defining knowledge translation. Canadian Medical Association Journal 181: 165-68. [CrossRef] [PubMed]

Tuck, E. 2009. Suspending damage: A Letter to Communities. Harvard Educational Review 79: 409-28. [CrossRef]

Tuck, E., W. Yang, and L.T. Smith. 2018. Indigenous and Decolonising Studies in Education: Mapping the Long View. New York: Routledge.

UNESCO. 2019. Available online: http://www.unesco.org/new/en/natural-sciences/priority-areas/links/relatedinformation/what-is-local-and-indigenous-knowledge (accessed on 11 December 2019).

Wallerstein, N., and B. Duran. 2006. Using community-based participatory research to address health disparities. Health Promotion Practice 7: 312-23. [CrossRef] [PubMed]

(C) 2019 by the authors. Licensee MDPI, Basel, Switzerland. This article is an open access article distributed under the terms and conditions of the Creative Commons Attribution (CC BY) license (http://creativecommons.org/licenses/by/4.0/). 